\title{
Extreme intrafamilial variability of Saudi brothers with primary hyperoxaluria type I
}

This article was published in the following Dove Press journal:

Therapeutics and Clinical Risk Management

27 August 2012

Number of times this article has been viewed

\author{
Majid Alfadhel' \\ Khalid A Alhasan ${ }^{2}$ \\ Mohammed Alotaibi ${ }^{3}$ \\ Khalid Al Fakeeh ${ }^{4}$ \\ 'Division of Genetics, Department \\ of Pediatrics, King Saud bin Abdulaziz \\ University for Health Sciences, \\ King Abdulaziz Medical City, Riyadh, \\ Saudi Arabia; ${ }^{2}$ Division of Nephrology \\ Department of Pediatrics, King Saud \\ University King Khalid University \\ Hospital, Riyadh, Saudi Arabia; \\ ${ }^{3}$ Department of Radiology, King Saud \\ bin Abdulaziz University for Health \\ Sciences, King Abdulaziz Medical City, \\ Riyadh, Saudi Arabia; ${ }^{4}$ Division of \\ Nephrology, Department of Pediatrics, \\ King Saud bin Abdulaziz University \\ for Health Sciences, King Abdulaziz \\ Medical City, Riyadh, Saudi Arabia
}

Background: Primary hyperoxaluria type 1 (PH1) is characterized by progressive renal insufficiency culminating in end-stage renal disease, and a wide range of clinical features related to systemic oxalosis in different organs. It is caused by autosomal recessive deficiency of alanine:glyoxylate aminotransferase due to a defect in $A G X T$ gene.

Case report: Two brothers (one 6 months old; the other 2 years old) presented with acute renal failure and urinary tract infection respectively. PH1 was confirmed by high urinary oxalate level, demonstration of oxalate crystals in bone biopsy, and pathogenic homozygous known $A G X T$ gene mutation. Despite the same genetic background, same sex, and shared environment, the outcome of the two siblings differs widely. While one of them died earlier with end-stage renal disease and multiorgan failure caused by systemic oxalosis, the older brother is pyridoxine responsive with normal development and renal function.

Conclusion: Clinicians should be aware of extreme intrafamilial variability of PH1 and international registries are needed to characterize the genotype-phenotype correlation in such disorder.

Keywords: primary hyperoxaluria, oxalosis, $\mathrm{PH} 1$, intrafamilial variability

\section{Introduction}

Primary hyperoxaluria type 1 (MIM\#259900) (PH1) is an autosomal recessive disorder due to deficiency of alanine:glyoxylate aminotransferase (AGT), which catalyzes the conversion of glyoxylate to glycine. This results in an increase of the glyoxylate pool, which is converted to oxalate. This forms insoluble calcium salts that accumulate in kidneys and target organs including bone marrow, retina, oral cavity, peripheral nerves, vascular system, thyroid, heart, and many more. While the age of onset can vary, the classical presentation starts at childhood with nephrolithiasis or nephrocalcinosis, impairment in renal function, and progression to end-stage renal disease. ${ }^{1-4}$ Diagnosis relies on measurement of 24 hours of urine collection of oxalate, plasma oxalate level, enzymatic assay of AGT catalytic activity from a liver biopsy, and DNA molecular testing of the $A G X T$ gene, which can detect $50 \%-70 \%$ of mutations. Treatment includes: maintenance of high fluid intake; pyridoxine supplements for those who are pyridoxine responsive; and use of potassium or sodium citrate or neutral orthophosphate and magnesium oxide to minimize stone formation. ${ }^{2-5}$ Little is known about the intrafamilial clinical heterogeneity in PH1. We describe two brothers with different outcomes. Despite having the same $A G X T$ mutation, one brother died in early infancy, while the older brother, who has a milder phenotype with normal development, responded to pyridoxine administration. 


\section{Clinical report}

\section{Patient I}

Patient 1 was the product of a full-term normal spontaneous vaginal delivery born to first-cousin Saudi parents with appropriate growth parameters and no significant antenatal history. He was apparently well until 6 months of age, at which point he demonstrated poor feeding and decreased activity for 10 days. After gradual deterioration, he presented to the emergency department with shortness of breath and anuria. Physical examination showed a nondysmorphic infant with appropriate growth parameters including weight: $8.7 \mathrm{~kg}$ (10-25th percentile), height: $64.5 \mathrm{~cm}$ (5th percentile), and head circumference: $42 \mathrm{~cm}$ ( 5 th percentile). He was pale, irritable, hypertensive, and edematous. Lab investigations were consistent with acute renal failure, with urea $>44 \mathrm{mmol} / \mathrm{L}$ $(1.1-8 \mathrm{mmol} / \mathrm{L})$, creatinine $=1614 \mathrm{mmol} / \mathrm{L}(18-35 \mathrm{umol} / \mathrm{L})$, $\mathrm{K}=5.6 \mathrm{mmol} / \mathrm{L}(4.1-5.3 \mathrm{mmol} / \mathrm{L})$, and bicarbonate $5 \mathrm{mmol} / \mathrm{L}$ (20-28 mmol/L). Therefore, the patient was admitted to the pediatric intensive care unit (PICU) and started on renal replacement therapy. However, the patient did not improve despite continuous dialysis and other supportive therapy. Renal ultrasound and computed tomography scan showed bilateral severe nephrocalcinosis with mild to moderate hydronephrosis (Figure 1). Serum lactate was high approaching $20 \mathrm{mmol} / \mathrm{L}(0.5-2.2 \mathrm{mmol} / \mathrm{L})$. Bone biopsy showed deposits of crystalline material with features compatible with oxalate crystals. Urine collection for oxalate was not performed because the patient was anuric. Despite full support in PICU, he did not improve. He developed multiorgan failure due to systemic oxalosis and subsequently died at 7 months of age.

\section{Patient 2}

Patient 2 was the product of a full-term normal spontaneous vaginal delivery with appropriate growth parameters and

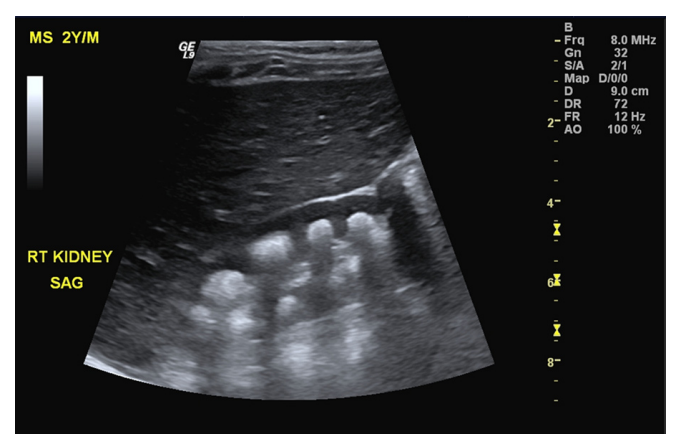

Figure I Sagittal ultrasound of the right kidney revealing presence of multiple crescent-shaped hyperechoic foci involving the renal pyramids consistent with renal medullary nephrocalcinosis. no significant antenatal history. He was apparently well until 2 years of age when he was admitted with symptoms of a urinary tract infection. Physical examination showed a weight of $13 \mathrm{~kg}$ (50-75th percentile), height of $85 \mathrm{~cm}$ (50th percentile), a macrocephalic child with head circumference of $52 \mathrm{~cm}$ ( $>97$ th percentile) (of note, his father's head circumference was $61 \mathrm{~cm}[>97$ th percentile]). At that time, his brother was admitted to PICU. Therefore, serial 24 hours of urine collection of oxalate was collected, which confirmed hyperoxaluria $=1.14 \mathrm{mmol} / \mathrm{L}(0.14-0.42 \mathrm{mmol} / \mathrm{L})$. Renal ultrasound showed bilateral medullary nephrocalcinosis (Figure 2). Urine aminoacids, calcium/creatinine ratio, renal function, electrolytes, and liver enzymes were all within the normal range. Bone X-ray showed no osteopenia or signs of rickets. Thyroid function test was normal and echocardiogram showed normal cardiac function.

Patient 2 started on high fluid intake, polycitra, and pyridoxine $6 \mathrm{mg} / \mathrm{kg} /$ day and showed more than a $50 \%$ reduction in urinary oxalate within 4 weeks, which was $0.58 \mathrm{mmol} / \mathrm{L}$ normalized after 2 months to $0.32 \mathrm{mmol} / \mathrm{L}$, and he continued to have normal growth and normal urinary oxalate. Currently, at the age of 3 years he shows appropriate growth parameters and normal urinary oxalate at the same dose of pyridoxine.

After obtaining informed consent from the parents, the $A G X T$ gene was analyzed by polymerase chain reaction and sequencing of both the DNA strand of the entire coding region and the highly conserved exon-intron splice junctions which revealed homozygous missense mutation in exon 2 of $A G X T$ gene, c.187G > C (p.Gly63Arg). ${ }^{6}$ The parents were tested and found to be carriers for this mutation.

\section{Discussion}

The clinical outcome of PH1 is variable, ranging from early death in infancy to the late-onset form with occasional stones

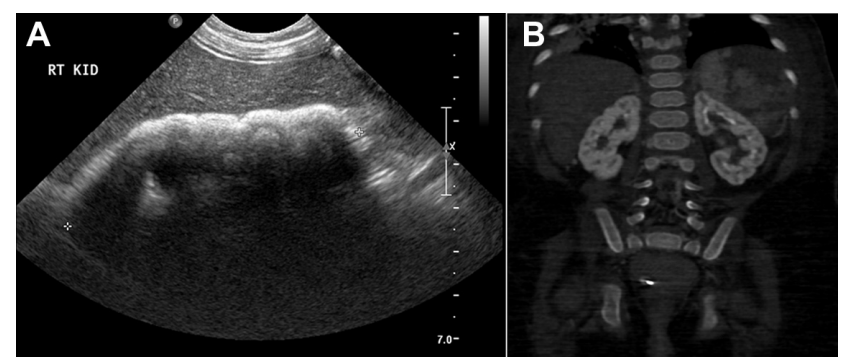

Figure 2 Radiological findings in patient 2.

Notes: (A) Ultrasound of the right kidney obtained in sagittal view demonstrates diffuse echogenicity involving the renal parenchyma. (B) Coronal reconstructed unenhanced computed tomography scan of the abdomen showed diffuse increased attenuation of both kidneys with more medullary increased density as compared to the renal cortex consistent with advanced nephrocalcinosis. 
diagnosed in adulthood. ${ }^{7}$ In this report we demonstrate the intrafamilial variability of the clinical outcomes of two brothers with PH1. Although they shared the same environment, sex, and $A G X T$ mutations, they differed in their degrees of oxalosis. The younger brother died at 7 months despite extensive support after multiorgan failure preceded by acute renal failure, while the older brother is pyridoxine-respondent with normal renal function.

There are few reports in the literature describing different outcomes in siblings with PH1. Frishberg et al described a family who demonstrated the extreme of intrafamilial phenotypic variability. ${ }^{8}$ One baby presented in utero with massive nephrocalcinosis and died at the age of 3 days. Four siblings diagnosed between 2 and 7 months of age developed end-stage renal disease associated with severe oxalosis. All died before the age of 3 years, while one older brother was asymptomatic at the age of 20 years. In another report, two adult males were affected but their two younger adult sisters, who had the same mutation, remained free of symptoms. ${ }^{9}$ Additionally, 12 adults with the same mutation (p.Ile244Thr) showed different outcomes and clinical phenotypes. ${ }^{10}$

Suggested reasons for this heterogeneity include differences in the activity level of other enzymes essential in oxalate synthesis, modifier genes, the amount of oxalate precursors in the diet, renal oxalate handling, absorption of dietary oxalate, hydration status, infections, and urinary crystallization factors. ${ }^{11}$ The causes for a poorer outcome in an infant with the same mutation as an older sibling have not been established. However, it may be related to a low glomerular filtration rate in infants, which predisposes them to earlier oxalate deposition. Another reason could be related to normal variation in the number of nephrons present at birth. ${ }^{12}$

Interestingly, the surviving child in this report is pyridoxine-respondent. This is confirmed by the reduction of the oxalate level by more than $50 \%$ within 4 weeks after starting the treatment with pyridoxine. Pyridoxine is an important precursor of the AGT cofactor, which is pyridoxal $5^{\prime}$-phosphate. Although the exact mechanism is not clear, it has been postulated that pyridoxine may increase the proportion of AGT that has a bound co-factor. ${ }^{11}$ There are several reports that have shown pyridoxine administration reduces oxalate excretion and oxalate level in $25 \%-50 \%$ of cases. ${ }^{13,14}$ Many studies suggest that the most common $A G X T$ mutation, c.508G > A (p.Gly170Arg), is associated with pyridoxine responsiveness. ${ }^{4,11}$

Another missense mutation reported to be associated with pyridoxine responsiveness is c. $454 \mathrm{~T}>\mathrm{A}$ (p.Phe152Ile).$^{15}$
The pyridoxine responsive child in this report has a c. $187 \mathrm{G}>\mathrm{C}$ (p.Gly63Arg) mutation, which was not reported previously as pyridoxine-responsive and it is extremely difficult from our report to conclude the association of such a mutation with pyridoxine responsiveness. This demonstrates the need for more studies with larger sample sizes focusing on genotype-phenotype correlation in PH1.

\section{Conclusion}

In summary, our report highlights the variability of the natural history of the PH1 even within the same family and with the same sex and genotype. International registries to accommodate more cases of PH1 will lead to a better understanding of the natural history and will facilitate well-designed treatment and outcome studies.

\section{Disclosure}

The authors report no conflicts of interest in this work.

\section{References}

1. Xu Y, Xiao YJ, Zhu K, et al. Unfolding the pathophysiological role of bioactive lysophospholipids. Curr Drug Targets Immune Endocr Metabol Disord. 2003;3(1):23-32.

2. Danpure CJ. Primary hyperoxaluria. In: Scriver CR, Beaudet AL, Sly WS, Valle D, editors. The Metabolic and Molecular Bases of Inherited Disease. New York: McGraw-Hill; 2001.

3. Danpure CJ, Jennings PR, Fryer P, Purdue PE, Allsop J. Primary hyperoxaluria type 1: genotypic and phenotypic heterogeneity. J Inherit Metab Dis. 1994;17(4):487-499.

4. Coulter-Mackie MB, White CT, Hurley RM, Chew BH, Lange D. Primary Hyperoxaluria Type 1. In: Pagon RA, Bird TD, Dolan CR, Stephens K, Adam MP, editors. GeneReviews ${ }^{\mathrm{TM}}$. Seattle: University of Washington; 1993.

5. Coulter-Mackie MB, Rumsby G. Genetic heterogeneity in primary hyperoxaluria type 1: impact on diagnosis. Mol Genet Metab. 2004; 83(1-2):38-46.

6. Williams EL, Acquaviva C, Amoroso A, et al. Primary hyperoxaluria type 1: update and additional mutation analysis of the AGXT gene. Hum Mutat. 2009;30(6):910-917.

7. Cochat P, Fargue S, Harambat J. Primary hyperoxaluria type 1: strategy for organ transplantation. Curr Opin Organ Transplant. 2010;15(5): 590-593.

8. Frishberg $\mathrm{Y}$, Rinat $\mathrm{C}$, Shalata A, et al. Intra-familial clinical heterogeneity: absence of genotype-phenotype correlation in primary hyperoxaluria type 1 in Israel. Am J Nephrol. 2005;25(3):269-275.

9. Mandrile G, Robbiano A, Giachino DF, et al. Primary hyperoxaluria: report of an Italian family with clear sex conditioned penetrance. Urol Res. 2008;36(6):309-312.

10. Lorenzo V, Alvarez A, Torres A, Torregrosa V, Hernández D, Salido E. Presentation and role of transplantation in adult patients with type 1 primary hyperoxaluria and the I244T AGXT mutation: single-center experience. Kidney Int. 2006;70(6):1115-1119.

11. Danpure C. Primary hyperoxaluria. In: Scriver CR, Beaudet AL, Sly WS, Valle D, editors. The Metabolic and Molecular Bases of Inherited Disease. Vol 2. 8th ed. New York: McGraw-Hill; 2001.

12. Luyckx VA, Brenner BM. Low birth weight, nephron number, and kidney disease. Kidney Int Suppl. 2005;(97):S68-S77. 
13. Toussaint C. Pyridoxine-responsive PH1: treatment. J Nephrol. 1998; 11 Suppl 1:49-50.

14. Marangella M. Transplantation strategies in type 1 primary hyperoxaluria: the issue of pyridoxine responsiveness. Nephrol Dial Transplant. 1999; 14(2):301-303.
15. Monico CG, Olson JB, Milliner DS. Implications of genotype and enzyme phenotype in pyridoxine response of patients with type I primary hyperoxaluria. Am J Nephrol. 2005;25(2):183-188.

\section{Publish your work in this journal}

Therapeutics and Clinical Risk Management is an international, peerreviewed journal of clinical therapeutics and risk management, focusing on concise rapid reporting of clinical studies in all therapeutic areas, outcomes, safety, and programs for the effective, safe, and sustained use of medicines. This journal is indexed on PubMed Central, CAS,
EMBase, Scopus and the Elsevier Bibliographic databases. The manuscript management system is completely online and includes a very quick and fair peer-review system, which is all easy to use. Visit http://www.dovepress.com/testimonials.php to read real quotes from published authors.

Submit your manuscript here: http://www.dovepress.com/therapeutics-and-clinical-risk-management-journal 